\title{
Two levels above and one level below pedicle screw fixation for the treatment of unstable thoracolumbar fracture with partial or intact neurology
}

\author{
Hitesh N Modi' ${ }^{1}$, Kook Jin Chung*1, Il Woo Seo', Hoi Soo Yoon², \\ Ji Hyo Hwang ${ }^{1}$, Hong Kyun Kim ${ }^{1}$, Kyu Cheol Noh${ }^{1}$ and Jung Han Yoo ${ }^{1}$
}

\author{
Address: ${ }^{1}$ Department of Orthopedics, Kangnam Sacred Heart Hospital, College of Medicine, Hallym University, Seoul, Korea and ${ }^{2}$ Department \\ of Radiology, Hallym Sacred Heart University Hospital, College of Medicine, Hallym University, Seoul, Korea \\ Email: Hitesh N Modi - hnm7678@yahoo.co.in; Kook Jin Chung* - chungkjmd@dreamwiz.com; Il Woo Seo - iwseomed@naver.com; \\ Hoi Soo Yoon - boundaries@naver.com; Ji Hyo Hwang - dr73@dreamwiz.com; Hong Kyun Kim - jaco-bass@naver.com; \\ Kyu Cheol Noh - happyshoulder@yahoo.co.kr; Jung Han Yoo - jhbyoo49@yahoo.co.kr \\ * Corresponding author
}

Published: 27 July 2009

Journal of Orthopaedic Surgery and Research 2009, 4:28 doi:10.1186/1749-799X-4-28

This article is available from: http://www.josr-online.com/content/4/I/28

(c) 2009 Modi et al; licensee BioMed Central Ltd.

This is an Open Access article distributed under the terms of the Creative Commons Attribution License (http://creativecommons.org/licenses/by/2.0), which permits unrestricted use, distribution, and reproduction in any medium, provided the original work is properly cited.
Received: 8 January 2009

Accepted: 27 July 2009

\begin{abstract}
Background: Treatment of unstable thoracolumbar fractures is controversial regarding short or long segment pedicle screw fixation. Although long level fixation is better, it can decrease one motion segment distally, thus increasing load to lower discs.

Methods: We retrospectively analyzed 3I unstable thoracolumbar fractures with partial or intact neurology. All patients were operated with posterior approach using pedicle screws fixed two levels above and one level below the fracture vertebra. No laminectomy, discectomy or decompression procedure was done. Posterior fusion was achieved in all. Post operative and at final follow-up radiological evaluation was done by measuring the correction and maintenance of kyphotic angle at thoracolumbar junction. Complications were also reported including implant failure.

Results: Average follow-up was 34 months. All patients had full recovery at final follow-up. Average kyphosis was improved from $26.7^{\circ}$ to $4.1^{\circ}$ postoperatively and to $6.3^{\circ}$ at final follow-up. And mean pain scale was improved from 7.5 to 3.9 postoperatively and to 1.6 at final follow-up, All patients resumed their activity within six months. Only 4 (I2\%) complications were noted including only one hardware failure.
\end{abstract}

Conclusion: Two levels above and one level below pedicle screw fixation in unstable thoracolumbar burst fracture is useful to prevent progressive kyphosis and preserves one motion segment distally.

\section{Background}

The thoracolumbar junction is the most common site of spinal injuries. The surgical treatment of unstable fractures and fracture dislocations of thoracolumbar spine remains controversial [1]. The goals of treatment in thoracolumbar fractures are restoring vertebral column stability and obtaining spinal canal decompression, leading to early mobilization of the patient. Either anterior, poste- 
rior or both approaches can be used to achieve fusion but the efficacy of either approach is the same [2,3]. However, posterior approach is less extensive, and most spine surgeons advocate posterior fusion as the treatment of choice for unstable thoracolumbar injuries $[4,5]$. The importance of early decompression and stabilization of unstable vertebral injuries has been emphasized in several reports $[4,6]$. Pedicle screw devices allow immediate stable fixation as the screws traverse all the three columns. Shortsegment (SS) pedicle instrumentation has become a popular method since Dick et al [7] introduced the "fixateur interne" device. Various techniques have since arisen for the management of unstable thoracolumbar fractures. Nowadays, controversy still exists over whether SS pedicle instrumentation is a suitable method. Biomechanical and clinical studies, however, have shown that when there is loss of more than $50 \%$ of the vertebral body height or angulations of the thoracolumbar junction of more than $20^{\circ}[8]$, acute spinal instability results, and the spinal segment will eventually fail with weight-bearing. Biomechanical studies have also shown that spinal instability results when there is a failure of at least two of Denis three columns [9]. Gurr et al [10] found that CD instrumentation placed two levels above and two levels below the injured level in an unstable calf spine model provided more stiffness than that in the intact spine. Krag [11] has suggested segmental pedicle fixation two levels above the kyphosis to prevent implant failure. Carl et al [4] reported that segmental transpedicular fixation two levels above the kyphosis should be used at the thoracolumbar junction where compressive forces act more anteriorly, whereas in the more lordotic middle and lower lumbar spine where the compressive forces act more posteriorly, no implant failure occurred with use of the one above-one below construct.

Here we present our results in unstable thoracolumbar fracture patients who were treated with pedicle screw fixation two level above and one level below the fracture vertebra, in order to preserve motion segment below the level of fracture. The purpose was to study the effectiveness of pedicle screw fixation, two levels above and one level below the fractured vertebra, in order to prevent postoperative kyphosis and high implant failure rate.

\section{Methods}

We retrospectively reviewed the results of unstable thoracolumbar fractures with partial or intact neurology in consecutive 31 patients who were operated between June 2004 and June 2006 at our institute by a single spine surgeon (Table 1). There were 18 males and 13 females with an average age of $40.6 \pm 12.7$ (range, 19 63 years). There were 7,13 and 11 patients who had fractures at T11, T12 and L1 level, respectively. 22 patients had injury due motor vehicle accident (MVA) and 9 had injury due to fall from height. Neurologic compromise was graded according to Frankel. There were 4, 7 and 20 patients with Frankel grade $\mathrm{C}, \mathrm{D}$ and $\mathrm{E}$ respectively. A postoperative neurologic examination was also performed in all patients 1 year later and the findings compared with the preoperative examination. Following a routine examination and $\mathrm{X}$ ray of the spine, computed tomography (CT) scan of the involved vertebra and adjacent vertebrae was carried out. McAfee's [12] system was used to classify the fractures. There were 14 unstable burst (UB) fractures, 9 translational (TRS) injuries and 8 flexion-distraction (FD) injuries. Frankel's grade system was used for assessment of neurological deficit on admission and subsequently in the follow-up.

Indication for surgical stabilization in patients who had partial or intact neurology was based on instability criteria of kyphotic deformity of more than $20^{\circ}$ and/or vertebral body height loss of more than 50 compared to vertebra below. The senior author (KJC) performed all surgeries. At surgery, the patients were placed in a hyperextended prone position with the abdomen hanging free, thus preventing excessive intraoperative bleeding and achieving a significant initial reduction of the spinal fracture. All patients were operated with single stage posterior surgery using pedicle screw instrumentation, two levels above and one level below the fractured vertebra (Figs. 1 and 2). All pedicle screws were inserted under $\mathrm{C}$-arm guidance. The rod was then fixed two levels above the fracture into the four screws and after that, torque was applied through the rod pusher to bring the vertebra back to the rod. Gentle distraction at the level of the fracture followed, restoring tension to the posterior longitudinal ligament (ligamentotaxis) and thereby, achieving anatomic reduction. None of our patients underwent discectomy and/or laminectomy and decompression procedure. All the patients had cross link fixation across the fracture site for preventing windshiled effect of construct with at least one pedicle screw fixation in the fractured vertebra. After the fixation, posterior fusion achieved using cancellous bone grafts harvested from posterior iliac crest.

All patients were managed with immobilization in a custom-molded thoracolumbosacral brace for three months postoperatively. All patients with age more than 40 years were investigated in form of DEXA (Dual Emission X-ray Absorptiometry) to evaluate BMD (bone mineral density) as a routine protocol in our clinic for the treatment of osteoporosis. The patients were followed with serial physical examinations and radiographs. With the use of lateral radiographs centered over the fracture level, kyphosis or lordosis was measured from the superior end-plate of the intact vertebra cephalad to the fracture to the inferior endplate of the vertebra caudad to the fracture. Progression was considered to be absent, minor, or major. Minor pro- 
Table I: Demographics of each patient with preoperative and postoperative kyphotic angle, neurological status and pain scale.

\begin{tabular}{|c|c|c|c|c|c|c|c|c|c|c|c|c|c|c|c|}
\hline \multirow[t]{2}{*}{ No } & \multirow[t]{2}{*}{ Sex } & \multirow[t]{2}{*}{$\underset{\text { (months) }}{\text { F-U }}$} & \multirow[t]{2}{*}{$\begin{array}{c}\text { Age } \\
\text { (years) }\end{array}$} & \multirow[t]{2}{*}{ Level } & \multirow[t]{2}{*}{$\begin{array}{l}\text { Injury } \\
\text { (cause) }\end{array}$} & \multirow[t]{2}{*}{$\begin{array}{c}\text { McAfee } \\
\text { (type) }\end{array}$} & \multirow[t]{2}{*}{$\begin{array}{c}\text { ISI } \\
\text { (Days) }\end{array}$} & \multicolumn{3}{|c|}{ Kyphosis angle } & \multicolumn{2}{|c|}{$\begin{array}{l}\text { Neurology } \\
\text { (Frankel) }\end{array}$} & \multicolumn{3}{|c|}{ Pain Scale (Dennis) } \\
\hline & & & & & & & & Preop & IMPO & Final & Preop & Final & Preop & IMPO & Final \\
\hline 1 & $M$ & 44 & 19 & LI & MVA & FD & 2 & 24 & 0 & 2 & $E$ & $E$ & 7 & 3 & 1 \\
\hline 2 & $M$ & 43 & 44 & TII & MVA & UB & 0 & 30 & 2.9 & 5.8 & $E$ & $E$ & 8 & 4 & 2 \\
\hline 3 & $\mathrm{~F}$ & 42 & 28 & $\mathrm{TI} 2$ & MVA & UB & 0 & 24.1 & 2 & 5.2 & C & $E$ & 7 & 4 & 1 \\
\hline 4 & $M$ & 42 & 60 & LI & MVA & UB & 1 & 25.3 & 2 & 4.5 & $E$ & $E$ & 9 & 5 & 2 \\
\hline 5 & $\mathrm{~F}$ & 36 & 43 & $\mathrm{TI} 2$ & MVA & UB & 6 & 27.4 & 2.4 & 5.1 & $\mathrm{D}$ & $E$ & 7 & 4 & 1 \\
\hline 6 & $\mathrm{~F}$ & 30 & 54 & TI2 & MVA & UB & 1 & 28.9 & 4.3 & 6.4 & $E$ & $E$ & 9 & 5 & 2 \\
\hline 7 & $M$ & 28 & 42 & TI2 & MVA & UB & I & 25.2 & 3 & 5.8 & $E$ & $E$ & 8 & 5 & 2 \\
\hline 8 & $\mathrm{~F}$ & 27 & 24 & TII & MVA & UB & 3 & 30.1 & 4.5 & 7.1 & $\mathrm{D}$ & $E$ & 9 & 4 & 3 \\
\hline 9 & $M$ & 49 & 28 & TI2 & MVA & UB & I & 29.5 & 3.4 & 5.7 & $E$ & E & 7 & 4 & 1 \\
\hline 10 & $M$ & 24 & 39 & TI2 & Fall & TRS & 1 & 29.3 & 4.2 & 5.8 & $D$ & $E$ & 7 & 5 & 1 \\
\hline 11 & $M$ & 48 & 63 & LI & Fall & UB & I & 29.3 & 5.3 & 7.7 & $E$ & $E$ & 8 & 4 & 2 \\
\hline 12 & $F$ & 47 & 50 & LI & MVA & FD & 5 & 29 & 5 & 6.5 & $C$ & $E$ & 8 & 5 & 2 \\
\hline 13 & $M$ & 44 & 39 & TI2 & Fall & TRS & 1 & 31.5 & 3.5 & 6.1 & $E$ & E & 9 & 6 & 2 \\
\hline 14 & $M$ & 29 & 42 & LI & MVA & UB & 0 & 25.4 & 4.2 & 6.9 & $D$ & E & 6 & 5 & 2 \\
\hline 15 & $M$ & 28 & 39 & TI2 & MVA & UB & 0 & 27.5 & 3.3 & 5.6 & $E$ & $E$ & 7 & 3 & 1 \\
\hline 16 & $M$ & 26 & 40 & LI & Fall & TRS & 10 & 26 & 10.5 & 16.4 & $E$ & $E$ & 6 & 3 & 1 \\
\hline 17 & $\mathrm{~F}$ & 26 & 59 & $\mathrm{~T} 12$ & MVA & TRS & 7 & 20.6 & 5.4 & 8.1 & C & $\mathrm{E}$ & 6 & 4 & 2 \\
\hline 18 & $\mathrm{~F}$ & 46 & 33 & TII & MVA & TRS & 4 & 20.5 & 7.3 & 8.6 & $E$ & $E$ & 7 & 2 & 1 \\
\hline 19 & $\mathrm{~F}$ & 42 & 26 & TI2 & Fall & TRS & 6 & 24 & 6 & 7.4 & $E$ & $E$ & 7 & 2 & 1 \\
\hline 20 & $M$ & 24 & 24 & TII & MVA & FD & 3 & 23 & 5 & 6.8 & $E$ & $E$ & 7 & 3 & 2 \\
\hline 21 & $M$ & 34 & 48 & $\mathrm{LI}$ & MVA & FD & 1 & 20.3 & 3.5 & 5.9 & $D$ & $E$ & 6 & 3 & 1 \\
\hline 22 & $M$ & 33 & 30 & TI2 & Fall & $\mathrm{FD}$ & 5 & 32.3 & 5.7 & 7.6 & $E$ & $E$ & 9 & 4 & 3 \\
\hline 23 & $\mathrm{~F}$ & 33 & 55 & TI2 & MVA & TRS & 4 & 31.5 & 2.5 & 3.8 & $E$ & $E$ & 8 & 3 & 1 \\
\hline 24 & $M$ & 32 & 62 & LI & MVA & FD & 1 & 24 & 4.3 & 5.8 & $E$ & $E$ & 7 & 4 & 1 \\
\hline 25 & $\mathrm{~F}$ & 32 & 23 & $\mathrm{LI}$ & Fall & FD & 8 & 21.8 & 4 & 5.8 & $D$ & $E$ & 7 & 3 & 2 \\
\hline 26 & $\mathrm{~F}$ & 36 & 43 & TII & MVA & UB & 6 & 22.8 & 3 & 5.2 & $E$ & $E$ & 7 & 3 & 2 \\
\hline 27 & $M$ & 24 & 23 & TII & Fall & UB & 3 & 20.5 & 4.6 & 6.5 & $E$ & $E$ & 7 & 3 & 1 \\
\hline 28 & $M$ & 24 & 56 & TII & Fall & TRS & 4 & 24.3 & 0 & 3.4 & $E$ & $E$ & 7 & 4 & I \\
\hline 29 & $\mathrm{~F}$ & 27 & 42 & LI & MVA & TRS & 7 & 35 & 8.4 & 9.8 & $D$ & $E$ & 9 & 4 & 2 \\
\hline 30 & $\mathrm{~F}$ & 26 & 37 & LI & MVA & UB & 3 & 30.3 & 3.7 & 4.6 & $E$ & $E$ & 9 & 5 & 2 \\
\hline 31 & $M$ & 29 & 42 & TI2 & MVA & FD & 14 & 35 & 3.2 & 5.9 & $C$ & $E$ & 8 & 5 & 3 \\
\hline
\end{tabular}

Abbreviations: F-U: Follow-Up; ISI: Injury Surgery Interval; IMPO: immediate post operative; MVA: motor vehicle accident; UB: Unstable burst fracture; TRS: translational injury; FD: flexion-distraction injury; HWF: hard ware failure; SWI: superficial wound infection.

gression was defined as kyphosis measuring 5 to $10^{\circ}$ more at the time of follow-up than it had on the immediate postoperative radiographs. Major progression was defined as an increase of $10^{\circ}$ or more compared with the measurement on the initial postoperative radiographs. Denis pain score were also compared statistically for each patient, immediate postoperatively and at the final follow-up, with preoperative pain score.

\section{Results}

Average follow-up was $34 \pm 8.2$ months (range, 24 49 months). Mean injury surgical interval was 3.5 days ranging from minimum 6 hours to maximum 14 days. Table 1 presents a master chart on the patients and their treatment, including patient parameters, mode of trauma, level of injury, type of fracture, injury surgery interval, kyphotic angles (pre-operative, post-operative, loss of kyphosis), neurological status, complications and pain evaluations.
The average pre-operative kyphotic angle was $26.7^{\circ}$ which improved to $4.1^{\circ}$ in the immediate post-operative period suggesting $84.6 \%$ correction ( $\mathrm{p}<0.0001$, paired $\mathrm{t}$-test) (Fig 1). At final follow-up it was $6.3^{\circ}$ suggesting $76.4 \%$ correction ( $\mathrm{p}<0.0001$, paired t-test) (Fig 2). Considering the change according to degree of progression, all but one patients showed no progression of kyphosis more than 5degree at final follow-up. Only one patient (patient 18) showed minor progression $\left(6.1^{\circ}\right)$ at the final follow-up. The average pre-operative vertebral height was $41.9 \%$ compared to the vertebra below the fracture, which improved to $76.2 \%$ in the immediate postoperative period. The loss of body height averaged $2.7 \%$ at the final follow-up, and the loss of kyphotic correction averaged $2.2^{\circ}$. Similarly, the average preoperative pain scale (Denis) was 7.5 , which was improved to 3.9 (49.1\%) immediate postoperatively. At final follow-up mean pain scale was 1.6 suggesting overall improvement of $79.1 \%$ than preoperative level. Our findings also suggested con- 


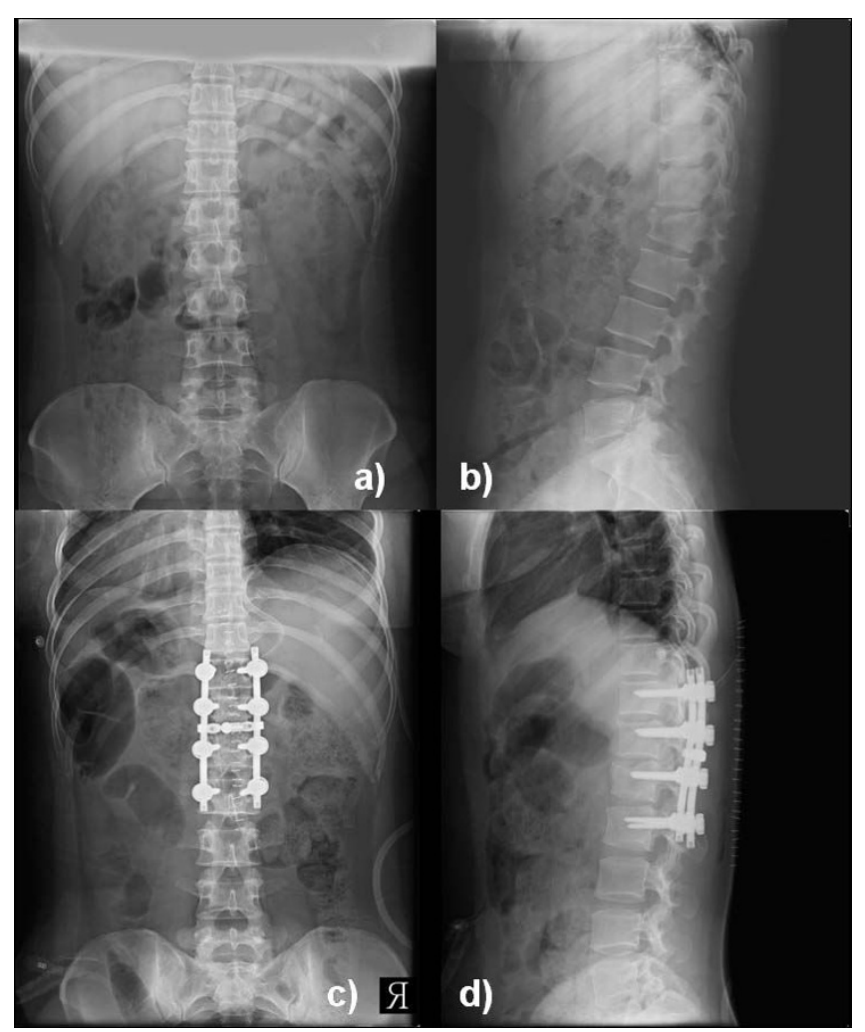

Figure I

showing preoperative a) AP and b) lateral radiogram of a patient with unstable LI fracture with kyphosis of 28-degrees. Immediate postoperative c) AP and d) lateral radiogram showed correction of kyphosis.

tinuous improvement in pain scale after the surgery. All the patients had Frankel grade E neurology at final followup suggesting all the patients were improved in neurological status after the surgery.

There were only four complications (12\%). Two patients (patient 12 and 19) had screw loosening. One was 63years-old male and other was 59-years-old female. They were osteoporotic patients which were confirmed with bone densitometry. Therefore screw loosening in them was thought to be due to osteoporosis. None of them had any deterioration in their functional activity. One 40 years male (patient 18) had breakage of right L1 screw; however there was no movement noted on flexion-extension radiogram and patient was symptomless. No treatment was done for the hardware failure in that patient. Finally, one 42-years-old male (patient 35) developed superficial wound infection which was treated with repeated dressings and parenteral antibiotics. His further follow-up was uneventful. All patients were able to return to their previous activity within six months of surgery and none of the patient had deterioration in neurology on regular follow- up. At final follow-up there was no instability detected on the flexion-extesion radiogram in all patients.

\section{Discussion}

Posterior transpedicular screw fixation initially was reported by Boucher in 1959 [13]. Since then, modern instrumentation systems have been developed. These systems control segmental motions in three dimensions, preserve motion segments, avoid long fusions, and provide a more stable construct [5]. As with all surgical implants; transpedicular screw instrumentation maintains reduction until bony union is achieved. Short-segment posterior fixation (SSPF) is the most common and simple treatment, offering the advantage of incorporating fewer motion segments in the fusion [14-17]. A review of the literature showed that SSPF alone led to a 9-54\% incidence of implant failure and re-kyphosis in the long-term follow-up, and $50 \%$ of the patients with implant failure had moderate-to-severe pain $[18,15,19]$. To prevent this, several techniques have been developed to augment the anterior column in burst fractures, such as transpedicular bone grafting $[18,20,15]$, placement of body augmenter [16], polymethylmethacrylate (PMMA) injection [21], anterior instrumentation and strut grafting [3], or long-segment posterior fixation (LSPF) $[14,22]$. In current study we retrospectively analyzed all patients who were treated with posterior approach using pedicle screw fixation two levels above and one level below the fracture vertebra, to study the effectiveness of fixation in preventing postoperative development of kyphosis and hardware failure.

Although SS pedicle instrumentation has been considered as a superior method, $[7,23]$ several studies showed that SS pedicle instrumentation had a high rate of failure $[18,19]$. Nevertheless, some studies demonstrated that clinical long-term results were favorable in patients who underwent SS pedicle instrumentation [23]. McLain et al [19], in their report of early failure of SSPF for thoracolumbar burst fracture noted three kinds of hardware failure with this fixation: progressive kyphosis secondary to the bending of screws, kyphosis secondary to osseous collapse or vertebral translation without bending of the hardware, and segmental kyphosis after a caudad screw in the lumbar construct broke. And they noted that untreated anterior instability, and pre-stressing of the screws when the rods were contoured in situ, resulted in a high rate of failure. Altay et al [24] reported that use of four pairs of screws (two above and two below) to lengthen the level arm of the construct would probably not only enhance the stability but also allow effective reduction of kyphotic deformity. SSPF alone can give good clinical and radiological outcomes for certain fractures in the thoracolumbar junction. Detection of such fractures in which SSPF, without supporting anterior column, is sufficient and does not lead to implant failure and correction loss. Tezeren and 


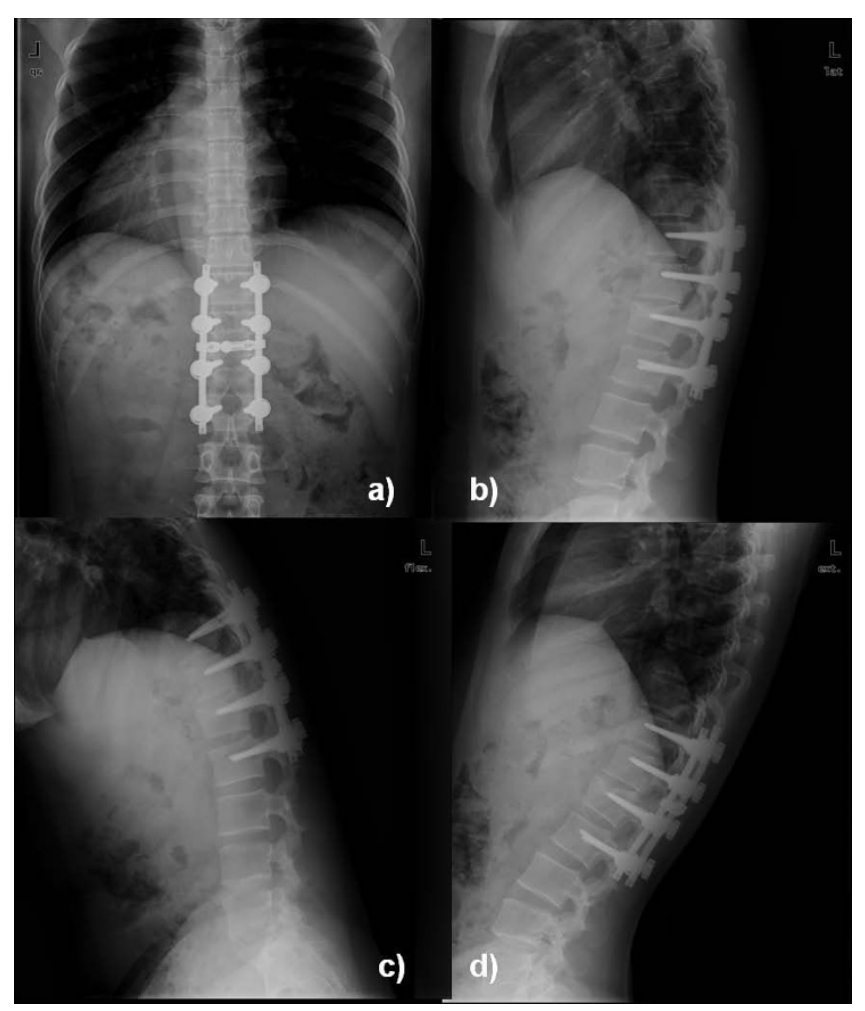

Figure 2

at final follow-up ( 3 years) a) AP and b) lateral radiogram showed maintenance of correction in kyphosis, and c) flexion and d) extension view showed good lumbar motion with maintenance of correction.

Kuru [25], in their study comparing short segment versus long segment fixation in thoracolumbar burst fractures, demonstrated that LS instrumentation is an effective way to manage thoracolumbar burst fractures. SS pedicle instrumentation had a high rate of failure. However, LS instrumentation prolonged the operative time and increased the amount of blood loss significantly. De Peretti et al [20] suggested that fixation by screw and hook constructs, gripping the two vertebrae above the lesion and screws and hooks gripping the first vertebra below the lesion, was an effective way to stabilize thoracolumbar junction burst fractures. Carl et al [4] also reported that segmental transpedicular fixation two levels above the kyphosis should be used at the thoracolumbar junction where compressive forces act more anteriorly. Therefore we prefer to put the pedicle screw two levels above the fracture site in order to prevent progressive kyphosis as well as hard ware failure. On the other hand preferring one level fixation distal to fracture site was to preserve the motion segment as much as possible in the lumbar level. Our result showed that we have achieved both our purposes with this fixation.
As all of the patients in our study had partial or intact neurology at the time of presentation, decision to operate was taken if they had kyphosis angle more than 20-degree and/or anterior vertebral body height more than 50\%; which suggested unstable fractures. Average preoperative kyphosis angle was $26.7^{\circ}$ preoperatively which improved to $4.1^{\circ}$ immediate postoperatively and maintained at $6.3^{\circ}$ at final follow-up. Our results suggested a success similar to LSPF construct reported in the literature. And we agree that fixing the fracture two levels above prevents progressive kyphosis development. Additionally evaluation of pain scale for all the patients suggested that our fixation strategy had been successful in improving the pain scales at final follow-up and all the patients were able to go back to their previous level of activity after the operation.

Butt et al [26] recently reported success of short segment pedicle screw fixation in thoracolumbar burst fractures; however the $40 \%$ (20 out of 50 patients) hardware failure rate that they reported is worrisome. We think that this high rate of implant failure is probably due to SSPF. In the present study we had only $12 \%$ (four patients out of 31 ) complication rate; one superficial wound infection, two screw loosening and one screw breakage. Screw loosening was found in patients with elder age which was probably due to their poor bone quality and therefore only one patient (42-years-old male) developed implant failure which is quite low than SSPF in the literature. We think that two level above and one level below pedicle screw fixation has high success rate in preventing hardware failure related complication similar to LSPF; and additionally we could save one motion segment distally as well in all the patients.

As our patients had partial neurological injury or intact neurology, we could preserve the lamina and other posterior structures in all patients. We feel that further study comparing the effectiveness of this construct in patients with laminectomy would be helpful to confirm the success of this technique. We think this could be the only weak factor in our study and we recommend further study in laminectomized patients in future. Additionally, we could not evaluate the union in all patients because all subjects did not undergo for CT scan at final follow-up. However, there was no instability noted on flexion-extension radiogram at final follow-up.

\section{Conclusion}

Our study reported prevention of progressive kyphosis development with the use of two levels above and one level below pedicel screw construct in unstable thoracolumbar burst fractures in patients with partial or intact neurology. Additionally it is helpful to preserve one 
motion segment distally at lumbar level and improving the pain scale at final follow-up.

\section{Competing interests}

The authors declare that they have no competing interests. Each author certifies that he has no commercial associations (e.g. consultancies, stock ownership, equity interests, patent/licensing arrangements, etc) that might pose a conflict of interest in connection with the submitted article.

\section{Authors' contributions}

HNM has contributed in conception and design of data, analysis and interpretation of data, drafting the manuscript and revising it critically, KJC has contributed in conception and design of data, drafting the manuscript and given the final approval of manuscript, IWS has contributed in drafting the manuscript and data analysis, HSY has contributed acquisition of data and revising it critically, $\mathrm{JHH}$ has contributed in acquisition of data, revising the manuscript critically and given the final approval, HKK has contributed in drafting the manuscript and designing of data and revising it critically, KCN has contributed in acquisition of data and analysis and interpretation of data, and JHY has contributed in acquisition and analysis of data. All authors read and approved the final manuscript.

\section{References}

I. Yue J, Sossan A, Selgrath C, Deutsch LS, Wilkens K, Testaiuti M, Gabriel JP: The treatment of unstable thoracic spine fractures with transpedicular screw instrumentation: a 3-year consecutive series. Spine 2002, 27(24):2782-2787.

2. Danisa OA, Shaffrey $\mathrm{Cl}$, Jane JA, Whitehill R, Wang GJ, Szabo TA, Hansen CA, Shaffrey ME, Chan DP: Surgical approaches for the correction of unstable thoracolumbar burst fractures: a retrospective analysis of treatment outcomes. J Neurosurg 1995, 83:977-83.

3. Kaneda K, Taneichi H, Abumi K, Hashimoto T, Satoh S, Fujiya M: Anterior decompression and stabilization with the Kaneda device for thoracolumbar burst fractures associated with neurological deficits. J Bone Joint Surg Am 1997, 79:69-83.

4. Carl AL, Tromanhauser SG, Roger DL: Pedicle screw instrumentation for thoracolumbar burst fractures and fracture-dislocation. Spine 1992, I7:S317-324.

5. Roy-Camille R, Saillant G, Mazel C: Internal fixation of the lumbar spine with pedicle screw plating. Clin Orthop 1986, 203:7-I7

6. Korovessis P, Baikousis A, Stamatakis M: Use of the Texas Scottish Rite Hospital Instrumentation in the treatment of thoracolumbar injuries. Spine 1997, 22:882-888.

7. Dick W, Kluger P, Magerl F, Woersdorfer O, Zach G: A new device for internal fixation of thoracolumbar and lumbar spine fractures: the fixateur interne. Paraplegia 1985, 23:225-232.

8. Nagel DA, Koogle TA, Piziali RL, Perkash I: Stability of upper lumbar spine following progressive disruption and the application of individual internal and external devices. J Bone Joint Surg Am 1981, 63:62-70.

9. Haher TR, Bergman M, O'Brien M, Felmly WT, Choueka J, Welin D, Chow $G$, Vassiliou A: The effect of three column of spine on the instantaneous axis of rotation in flexion and extension. Spine 1991, 16:S312-318.

10. Gurr KR, McAfee PC, Shih CM: Biomechanical analysis of anterior and posterior instrumentation systems after corpectomy: A calf-spine model. J Bone Joint Surg Am 1988, 70: | I82-91.
II. Krag $\mathrm{MH}$ : Biomechanics of thoracolumbar spinal fixation: $\mathbf{A}$ review. Spine 1991, 16:S84-99.

12. McAfee PC, Yuan HA, Fredrickson BE, Lubicky JP: The value of computed tomography in thoracolumbar fractures. An analysis of one hundred consecutive cases and a new classification. J Bone Joint Surg Am 1983, 65:46 I-473.

13. Boucher $\mathrm{HH}$ : A method of spinal fusion. J Bone Joint Surg Br 1959, 4I:248-259.

14. Akbarnia BA, Crandall DG, Burkus K, Matthews T: Use of long rods and a short arthrodesis for burst fractures of the thoracolumbar spine. A long-term follow-up study. J Bone Joint Surg Am I994, 76(I I): I629-1635.

15. Knop C, Bastian L, Lange U, Oeser M, Zdichavsky M, Blauth M: Complications in surgical treatment of thoracolumbar injuries. Eur Spine J 2002, I I (3):2 I 4-226.

16. Li KC, Hsieh $\mathrm{CH}$, Lee $\mathrm{CY}$, Chen TH: Transpedicle body augmenter: a further step in treating burst fractures. Clin Orthop Relat Res 2005, 436: I 19-125.

17. Parker JW, Lane JR, Karaikovic EE, Gaines RW: Successful shortsegment instrumentation and fusion for thoracolumbar spine fractures: a consecutive 4 I/2-year series. Spine 2000, 25(9): I I57-I I 70.

18. Alanay A, Acarolu E, Yazici M, Oznur A, Surat A: Short-segment pedicle instrumentation of thoracolumbar burst fractures: does transpedicular intracorporeal grafting prevent early failure. Spine 200I, 26(2):2I3-2I7.

19. McLain RF, Sparling E, Benson DR: Early failure of short-segment pedicle instrumentation of thoracolumbar fractures. A preliminary report. J Bone Joint Surg Am 1993, 75(2): I62-167.

20. De Peretti F, Hovorka I, Cambas PM, Nasr JM, Argenson C: Short device fixation and early mobilization for burst fractures of the thoracolumbar junction. Eur Spine J 1996, 5: I I 2- 120.

21. Cho DY, Lee WY, Sheu PC: Treatment of thoracolumbar burst fractures with polymethyl methacrylate vertebroplasty and short-segment pedicle screw fixation. Neurosurgery 2003, 53(6): I354-1360.

22. Gurr KR, McAfee PC: Cotrel-Dubousset instrumentation in adults. A preliminary report. Spine 1988, 13:510-520.

23. Rommens PM, Weyns F, Van Calenbergh F, Goffin J, Broos PL: Mechanical performance of the Dick internal fixator. A clinical study of 75 patients. Eur Spine J 1995, 4: I04- 109.

24. Altay M, Ozkurt B, Aktekin CN, Ozturk AM, Dogan O, Tabak AY: Treatment of unstable thoracolumbar junction burst fractures with short- or long- segment posterior fixation in magrel type a fractures. Eur Spine J 2007, I 6: I | 45- I I 55.

25. Tezeren G, Kuru I: Posterior fixation of thoracolumbar burst fracture. Short-segment pedicle fixation versus long-segment instrumentation. J Spinal Disord Tech 2005, I 8:485-488.

26. Butt MF, Farooq M, Mir B, Dhar AS, Hussain A, Mumtaz M: Management of unstable thoracolumbar spinal injuries by short segment pinal fixation. International Orthop 2007, 3 I :259-264.

\section{Publish with Bio Med Central and every scientist can read your work free of charge}

"BioMed Central will be the most significant development for disseminating the results of biomedical research in our lifetime. "

Sir Paul Nurse, Cancer Research UK

Your research papers will be:

- available free of charge to the entire biomedical community

- peer reviewed and published immediately upon acceptance

- cited in PubMed and archived on PubMed Central

- yours - you keep the copyright 